\title{
EXTRAFISCALIDADE DO ICMS: ICMS ECOLÓGICO E SUA COLABARAÇÃO PARA O DESENVOLVIMENTO SUSTENTÁVEL
}

\section{VALMIR CÉSAR POZZETTI}

Doutor em Biodireito/Direito Ambiental pela Université de Limoges/França. Mestre em Direito do Urbanismo e Meio ambiente pela Université de Limoges/França. Professor Adjunto da UFAM - Univ. Federal do Amazonas e da UEA - Universidade do Estado do Amazonas.

\section{BEATRIZ DE SOUZA CALDAS}

Mestranda do PPGDA - Programa de Pós-Graduação em direito ambiental da UEA - Universidade do Estado do Amazonas.

\section{DONALDO GARCIA JANA RIKER}

Mestrando do PPGDA - Programa de Pós-Graduação em direito ambiental da UEA - Universidade do Estado do Amazonas.

\section{OBJETIVOS DO TRABALHO}

O meio ambiente ao longo da existência humana sofre gradativamente com as atividades econômicas promovidas tanto pelas pessoas jurídicas privadas, quanto pelos entes federativos. A República Federativa do Brasil é um Estado Democrático de Direito, portanto possui não apenas prerrogativas, mas também deveres, entre eles o de garantir o desenvolvimento sustentável nacional.

Tendo em vista tais fundamentos, está pesquisa possui como objetivo analisar um dos tributos de competência estadual, qual seja o ICMS, mais especificamente, sob a perspectiva extrafiscal, ponderando a possibilidade de 


\section{Personalidade Acadêmica Homenageada:}

\section{Florisbal de Souza Del'OImo (Professor Convidado - UNICURITIBA)}

utilização para fins de incentivos de boas práticas ambientais por parte dos Municípios a serem estimuladas por meio do ICMS ecológico, em busca do desenvolvimento sustentável.

\section{METODOLOGIA UTILIZADA}

A metodologia a ser utilizada nesta pesquisa é a do método dedutivo, onde se fará diversas pesquisas e análises jurídicas para, deduzir de que forma a legislação poderá auxiliar na preservação/conservação ambiental. Quanto aos meios a pesquisa será bibliográfica, com consulta à doutrina, legislação, jurisprudência e casos reais; quanto aos fins a pesquisa será qualitativa, na tentativa de se trazer soluções eficazes à problemática ambiental.

\section{REVISÃO DE LITERATURA}

A Constituição Federal do Brasil de 1988 em seu art. 1ํ, caput, esclarece que o Brasil é um Estado Democrático de Direito: "Art. 1ํ A República Federativa do Brasil, formada pela união indissolúvel dos Estados e Municípios e do Distrito Federal, constitui-se em Estado Democrático de Direito e tem como fundamentos".

Essa afirmação possui grandes reflexos quanto a atuação Estatal, uma vez que a República Federativa do Brasil ao seguir o modelo do neoconstitucionalismo fixado pelo Texto Maior, não está mais limitada em abster-se, para não ferir direitos fundamentais dos cidadãos (prestação negativa), mas, ao contrário, possui o dever de concretizar, por meio de prestações positivas, os direitos fundamentais estabelecidos na Constituição Federal. Nesse sentido Agra esclarece que:

O neoconstitucionalismo tem como uma de suas marcas a concretização das prestações materiais prometidas pela sociedade, servindo como ferramenta para a implantação de Estado Democrático Social de Direito. Ele pode ser considerado como um movimento caudatário do pós-modernismo.

1BRASIL. Constituição da República Federativa do. Congresso Nacional, Brasília, 1988. 


\title{
Personalidade Acadêmica Homenageada: \\ Florisbal de Souza Del'OImo (Professor Convidado - UNICURITIBA)
}

\begin{abstract}
Dentre suas principais características podem ser mencionadas: positivação e concretização de catálogo de direitos fundamentais; b) onipresença dos princípios e das regras; c) inovações hermenêuticas; d) densificação da força normativa do Estado; e) da justiça distributiva ${ }^{2}$.
\end{abstract}

Destaca-se que o direito ao meio ambiente ecologicamente equilibrado, é considerado um direito fundamental de terceira dimensão, pois o rol de direitos fundamentais é exemplificativo. O direito ao meio ambiente ecologicamente equilibrado, está previsto no art. 225, caput, da CF/88. Neste sentido, Moraes esclarece que "modernamente, protege-se, constitucionalmente, como direitos de terceira geração os chamados direitos de solidariedade e fraternidade, que englobam o direito a um meio ambiente equilibrado [...]."

Com isso, por meio do modelo neoconstitucional estabelecido pelo atual Estado Democrático de Direito, o qual preconiza pela máxima efetiva dos direitos fundamentais, nota-se que pelo fato de o meio ambiente ecologicamente equilibrado encontrar-se abrangido no rol de direito fundamentais o Estado possui o dever de assegurá-lo.

Nesse contexto o próprio sistema jurídico constitucional proporciona ferramentas para que o Estado alcance os seus objetivos estabelecidos em seu próprio texto.

No tocante a Ordem econômica e Financeira e sua compatibilização com o desenvolvimento sustentável, a Constituição Federal possibilita que o Estado intervenha na economia para efetivar sua compatibilização, seguinte dispositivo:

Art. 170. A ordem econômica, fundada na valorização do trabalho humano e na livre iniciativa, tem por fim assegurar a todos existência digna, conforme os ditames da justiça social, observados os seguintes princípios: [...]omissis VI - defesa do meio ambiente, inclusive mediante tratamento diferenciado conforme o impacto ambiental dos produtos e serviços e de seus processos de elaboração e prestação; ${ }^{4}$ (gn).

\footnotetext{
${ }^{2}$ AGRA, Walber de Moura. Curso de direito Constitucional. 4 ed. Rio de Janeiro: Forense, 2008.

${ }^{3}$ MORAES, Alexandre de. Direito Constitucional. São Paulo: Atlas, 2012, p. 29.

${ }^{4}$ BRASIL. Constituição da República Federativa do. Congresso Nacional, Brasília, 1988.
} 


\section{Personalidade Acadêmica Homenageada: \\ Florisbal de Souza Del'OImo (Professor Convidado - UNICURITIBA)}

No entanto, aparentemente não é somente esse dispositivo que possibilita a proteção do meio ambiente ecologicamente equilibrado, no que tange especificamente no âmbito do Direto Ambiental Tributário, especula-se a possibilidade do manejo do art. art.158, parágrafo único, inciso II da Constituição Federal, como fundamento para a instituição do ICMS ecológico.

É importante esclarecer que o ICMS é uma espécie de tributo, nos termos art.3 do CTN e o fundamento jurídico constitucional para sua instituição encontra-se no art.155, II do Texto Maior, o qual atribui competência aos Estados e Distrito Federal para instituí-lo. Nesse sentido:

O ICMS é um tributo que possui finalidade fiscal, no entanto a Constituição federal possibilitou a seletividade deste tributo no seu art.155, § 2, III, ensejando assim a sua aplicabilidade sobre o prisma da extrafiscalidade. Afirma Costa (2015, p. 389) que "a regra em foco significa que o ICMS operará, também, como instrumento de extrafiscalidade, visando beneficiar os consumidores finais, que efetivamente absorvem o impacto econômico do imposto.." ${ }^{5}$

No tocante a extrafiscalidade Pozzetti e Campos $^{6}$ destacam que:

Portanto, pode-se concluir que, no Brasil, em matéria de Meio Ambiente não é possível o estabelecimento de impostos diretos; mas, dada a natureza das espécies tributárias, é possível a inclusão do tema Ecológico no campo do Direito Tributário, com o fim de sistematizar a tributação ambiental através da tributação extrafiscal, ou seja, através da tributação indireta.

Esse dispositivo estabelece que o ICMS poderá ser tributado de modo majorado ou minorado na medida da essencialidade das mercadorias e dos serviços, com isso é aparentemente vislumbra-se a possibilidade de manejarmos o caráter extrafiscal do presente tributo com intuito de garantirmos a preservação do meio ambiente natural, assim como no desenvolvimento sustentável, tendo como

\footnotetext{
${ }^{5}$ COSTA, Regina Helena. Curso de Direito Tributário. São Paulo: Saraiva, 2015.

6 POZZETTI, Valmir César e CAMPOS, Jalil Fraxe. ICMS ECOLÓGICO: UM DESAFIO À SUSTENTABILIDADE ECONÔMICO AMBIENTAL NO AMAZONAS. Revista Jurídica do Unicuritiba. vol. 02, n. 47, Curitiba, 2017. pp. 251-276 DOI: 10.6084/m9.figshare.5186836.p. 257
} 


\title{
Personalidade Acadêmica Homenageada:
}

Florisbal de Souza Del'Olmo (Professor Convidado - UNICURITIBA)

ponto de partida a essencialidade dos bens naturais, uma vez que estes são escassos.

$\mathrm{Na}$ Constituição Federal, encontra-se o possível fundamento para a instituição do ICMS ecológico, mediante criação de Leis Estaduais ou, no caso de Territórios, Lei Federal, para tal finalidade, a depender do caso. Nos termos do respectivo dispositivo constitucional:

\begin{abstract}
Art. 158. Pertencem aos Municípios: [...]omissis IV - vinte e cinco por cento do produto da arrecadação do imposto do Estado sobre operações relativas à circulação de mercadorias e sobre prestações de serviços de transporte interestadual e intermunicipal e de comunicação. Parágrafo único. As parcelas de receita pertencentes aos Municípios, mencionadas no inciso IV, serão creditadas conforme os seguintes critérios: [...]omissis II - até um quarto, de acordo com o que dispuser lei estadual ou, no caso dos Territórios, lei federal. $^{7}$
\end{abstract}

Portanto, observa-se que com base na cláusula geral, "de acordo com o que dispuser lei estadual", aparentemente abra-se a possibilidade de ser utilizada para proteção ambiental, de modo a condicionar o repasse dessa fração a determinados requisitos, uma vez que parte dos estados já instituíram o ICMS ecológico, sob este fundamento.

\section{RESULTADOS OBTIDOS OU ESPERADOS}

Tendo como base os posicionamentos doutrinários e a legislação brasileira, constata-se a possibilidade de aprofundarmos ainda mais o estudo da hipótese trazida à baila, uma vez que o Ordenamento Jurídico brasileiro deve ser interpretado e aplicado de modo sistemático, levando sempre em conta o aspecto teleológico e axiológico do Ordenamento com um todo.

Observa-se, que apesar de muitas vezes nos depararmos com certas regras aparentemente contraditória, por meio das técnicas apontadas anteriormente, o operador do direito tem a missão de compatibilizá-las.

\footnotetext{
${ }^{7}$ BRASIL. Constituição da República Federativa do. Congresso Nacional, Brasília, 1988.
} 


\section{Personalidade Acadêmica Homenageada:}

\section{Florisbal de Souza Del'OImo (Professor Convidado - UNICURITIBA)}

Aparentemente é isso que ocorre na presente pesquisa, tendo em vista que de um lado temos o dever de preservação do meio ambiente ecologicamente equilibrado e do outro a instituição de um tributo (ICMS) que possui como fato gerado a circulação de mercadoria.

Ou seja, em tese quanto mais atividade industrial e econômica, mais o Estado irá arrecadar, uma vez que nesse cenário a tendência é aumentar a circulação de mercadorias e consequentemente a arrecadação Estatal. No entanto, não podemos perder de vista o desenvolvimento sustentável, assim como o princípio do protetor-recebedor, sem, contudo, deixarmos de lado a atividade econômica e a finalidade arrecadatória dos impostos perante os entes federativos.

Pelo exposto, a priori acreditamos na possibilidade do manejo do ICMS, sob a sua perspectiva extrafiscal com a finalidade de induzirmos condutas positivas dos Municípios voltadas para o desenvolvimento sustentável, aplicando o princípio do protetor-recebedor, por meio do ICMS ecológico, sendo este mais um mecanismo garantidor do direito fundamental ao meio ambiente ecologicamente equilibrado.

\section{TÓPICO CONCLUSIVOS}

Através da metodologia e métodos escolhidos, foi possível alcançarmos algumas conclusões, quais sejam: a compatibilidade no Ordenamento jurídico brasileiro entre a obrigação estatal de assegurar o meio ambiente ecologicamente equilibrado e a função arrecadatória estatal; a possibilidade da utilização do imposto ICMS em seu aspecto extrafiscal e a possibilidade de imposição requisitos a serem cumpridos pelos Municípios que tenham a pretensão de serem beneficiados com o ICMS ecológico.

Com base nas respostas obtidas, chamamos a atenção para a seguintes questões, quais seriam os melhores requisitos a serem instituídos em cada estado da federação para que se alcance o resultado pretendido? Como podemos induzir os Municípios a aderirem está política ambiental? De que modo será feita a 


\section{Personalidade Acadêmica Homenageada:}

Florisbal de Souza Del'Olmo (Professor Convidado - UNICURITIBA)

fiscalização da manutenção dos requisitos após a concessão do ICMS ecológico para o Município? Será muito oneroso para o ente promover está fiscalização?

Tendo em vista estas novas questões levantadas, com base no resultado da pesquisa, podemos apontar como um novo caminho a promoção de estudos promovidos por equipes multidisciplinares, capazes de constatar dentro da circunscrição do estado, em quais pontos cada região do estado está mais deficiente do ponto de vista ambiental, para que ao elaborar a Lei Estadual tais estudos sejam levados em consideração, na busca de uma maior adequação regional.

Portanto, esta pesquisa traz umas novas perspectivas do ponto de vista de sua interpretação e implementação, uma vez que é proposto maior efetividade no que diz respeitos às necessidades de cada região, bem como a manutenção dos requisitos para a manutenção do benefício.

\section{REFERÊNCIAS}

AGRA, Walber de Moura. Curso de direito Constitucional. $4^{\mathrm{a}}$ ed. Rio de Janeiro: Forense, 2008.

BRASIL. Constituição da República Federativa do Congresso Nacional, Brasília, 1988.

COSTA, Regina Helena. Curso de Direito Tributário. São Paulo: Saraiva, 2015.

MORAES, Alexandre de. Direito constitucional. São Paulo: Atlas, 2012, p. 29.

POZZETTI, Valmir César e CAMPOS, Jalil Fraxe. ICMS ecológico: um desafio à sustentabilidade econômico ambiental no amazonas. Revista Jurídica do Unicuritiba. vol. 02, $\mathrm{n}^{\circ}$. 47, Curitiba, 2017. pp. 251-276 DOI: 10.6084/m9.figshare.5186836.p. 257 